\title{
Understanding Time Series Patterns of Weight and Meal History Reports in Mobile Weight Loss Intervention Programs: Data-Driven Analysis
}

\author{
Junetae Kim ${ }^{1,2,3^{*}}$, PhD; Hye Jin Kam ${ }^{4 *}$, PhD; Youngin Kim ${ }^{5,6}$, MD; Yura Lee ${ }^{7}$, MD, PhD; Jae-Ho Lee ${ }^{7,8}, \mathrm{MD}, \mathrm{PhD}$ \\ ${ }^{1}$ Graduate School of Cancer Science and Policy, National Cancer Center, Goyang-si, Republic of Korea \\ ${ }^{2}$ Cancer Data Center, National Cancer Control Institute, National Cancer Center, Goyang-si, Republic of Korea \\ ${ }^{3}$ Healthcare AI Team, Healthcare Platform Center, National Cancer Center, Goyang-si, Republic of Korea \\ ${ }^{4}$ AIMMED Co, Ltd, Seoul, Republic of Korea \\ ${ }^{5}$ Noom Inc., New York, NY, United States \\ ${ }^{6}$ Department of Biomedical Systems Informatics, Yonsei University College of Medicine, Seoul, Republic of Korea \\ ${ }^{7}$ Department of Information Medicine, Asan Medical Center, University of Ulsan College of Medicine, Seoul, Republic of Korea \\ ${ }^{8}$ Department of Emergency Medicine, Asan Medical Center, University of Ulsan College of Medicine, Seoul, Republic of Korea \\ *these authors contributed equally
}

\section{Corresponding Author:}

Jae-Ho Lee, MD, PhD

Department of Information Medicine

Asan Medical Center

University of Ulsan College of Medicine

88, Olympic-ro 43-gil, Songpa-gu

Seoul, 05505

Republic of Korea

Phone: 8230103350

Fax: 8230103360

Email: rufiji@gmail.com

\begin{abstract}
Background: Mobile apps for weight loss provide users with convenient features for recording lifestyle and health indicators; they have been widely used for weight loss recently. Previous studies in this field generally focused on the relationship between the cumulative nature of self-reported data and the results in weight loss at the end of the diet period. Therefore, we conducted an in-depth study to explore the relationships between adherence to self-reporting and weight loss outcomes during the weight reduction process.

Objective: We explored the relationship between adherence to self-reporting and weight loss outcomes during the time series weight reduction process with the following 3 research questions: "How does adherence to self-reporting of body weight and meal history change over time?", "How do weight loss outcomes depend on weight changes over time?", and "How does adherence to the weight loss intervention change over time by gender?"

Methods: We analyzed self-reported data collected weekly for 16 weeks (January 2017 to March 2018) from 684 Korean men and women who participated in a mobile weight loss intervention program provided by a mobile diet app called Noom. Analysis of variance (ANOVA) and chi-squared tests were employed to determine whether the baseline characteristics among the groups of weight loss results were different. Based on the ANOVA results and slope analysis of the trend indicating participant behavior along the time axis, we explored the relationship between adherence to self-reporting and weight loss results.
\end{abstract}

Results: Adherence to self-reporting levels decreased over time, as previous studies have found. BMI change patterns (ie, absolute BMI values and change in BMI values within a week) changed over time and were characterized in 3 time series periods. The relationships between the weight loss outcome and both meal history and self-reporting patterns were gender-dependent. There was no statistical association between adherence to self-reporting and weight loss outcomes in the male participants.

Conclusions: Although mobile technology has increased the convenience of self-reporting when dieting, it should be noted that technology itself is not the essence of weight loss. The in-depth understanding of the relationship between adherence to self-reporting 
and weight loss outcome found in this study may contribute to the development of better weight loss interventions in mobile environments.

(J Med Internet Res 2020;22(8):e17521) doi: 10.2196/17521

\section{KEYWORDS}

weight loss; self-reporting; adherence; mobile weight loss intervention; diet

\section{Introduction}

Mobile apps are widely used for tracking weight loss [1-3]. A major feature of these apps is providing users with self-reporting capabilities regarding their lifestyle and health-related measurements [1-3].

Self-reporting has been recognized as a very important behavioral treatment method for weight loss [4-9] because it provides diet participants with a continuous feedback loop that can modify behaviors to achieve goals through the process of observation, evaluation, and reinforcement [5,10]. Indeed, several empirical studies have shown a positive relationship between adherence to self-reporting and satisfactory weight loss outcomes $[4,5,7]$. For these reasons, considerable research has been conducted regarding adherence to self-reporting in the field of weight loss research $[6,8,11]$. These studies commonly suggest the expectation that the use of mobile technology will improve adherence to self-reporting $[6,7,12]$.

Compared to traditional tools, mobile technology's portability has made it easier and more effective to monitor and control one's weight [4,9,13-15]. In addition, the use of mobile technology such as smartphones and wearable devices enables researchers to explore new topics by collecting data that could not previously be gathered. Specifically, a representative research question related to new data may demonstrate the relationship between characteristics of adherence to self-reporting and weight loss outcomes $[4,15,16]$. Another research question may explore the differences in adherence to self-reporting during the diet in terms of demographic characteristics such as gender and sociocultural aspects such as race [17-22]. These studies have found that adherence to self-reporting decreases over time [4,16,21,23,24] and is dependent on demographics [17-22].

However, an in-depth understanding is lacking regarding the relationship between weight loss outcomes and the dynamics of adherence to self-reporting according to specific groups. Attempts at an in-depth understanding of this relationship is very important for several reasons. First, given that demographic characteristics affect both adherence to self-reporting and dietary approaches [17-22], researchers may gain a fundamental understanding of how certain groups respond to weight loss interventions. Second, researchers may understand the mechanism of weight changes during the weight loss process that involves a series of weight gain, loss, and regain cycles [21-23]. Ultimately, gaining an in-depth understanding of these matters will contribute to designing better weight loss programs suitable for mobile apps.

Thus, this study aimed to analyze the relationship between weight loss outcomes and the dynamics of adherence to self-reporting. To that end, we analyzed self-reported data that were aggregated on a weekly basis for 16 weeks, from January 2017 to March 2018, from 684 Korean men and women who participated in a mobile weight loss intervention program provided by a commercial smartphone app.

The following 3 research questions were explored and answered: How does adherence to self-reporting on body weight and meal history change over time? How do weight loss outcomes depend on weight changes over time? How does adherence to the weight loss intervention change over time by gender?

\section{Methods}

\section{Mobile Weight Loss Intervention}

The mobile intervention program for this study was delivered through a commercially available mobile coaching program called Noom [25]. During the 16-week program, users were asked to $\log$ their meals, exercise, and weight data using this app [25]. In-app articles about healthy dietary intake and promotions to encourage physical activities were provided on a daily basis [25]. The articles were adapted by physicians, clinical dietitians, and clinical psychologists and based on studies provided by the American Diabetes Association, American Heart Association, and Centers for Disease Control and Prevention.

All coaches were registered dietitians, and they were supervised weekly by a clinical psychologist. They helped users set weekly goals and provided personalized feedback based on each user's lifestyle. Messages were sent to the users at least twice per week.

\section{Measurements}

\section{Weight Entry Trends}

The frequency of weight entries was analyzed. In most health care app research programs, user adherence to a certain intervention has often been measured by the frequency of self-reporting $[4,24,26,27]$. Therefore, the number of body weight entries per week served as a trustworthy variable in measuring the degree of adherence to the weight loss intervention in this research [4,24,26,27].

The study participants reported their weight through the app. After reporting, weight-related menu-usage logs were automatically stored on a server. The collected usage log data were summed at weekly intervals to generate data indicating adherence to weight-reporting activity over 16 weeks, for each subject.

\section{BMI Trends}

BMI is often used to determine whether a person is within a healthy weight range based on their height $[4,14,28]$. Since this 
is calculated by dividing weight by height $\left(\mathrm{kg} / \mathrm{m}^{2}\right)$, the BMI value represents relative weight with respect to height $[29,30]$. In other words, BMI values indicate whether a person is "underweight," "healthy," "overweight," or "obese" [4,14,28]. Because of its ease of interpretation and satisfactory explanatory power, BMI has been used instead of basic weight measurements for many diet-related studies on web and mobile weight tracking environments [4,14,25,31-33].

Participants reported their body weight daily through Noom. The daily BMI values for each participant were calculated by dividing the daily reported weights by their initially entered height values, and the daily results were averaged on a weekly basis.

BMI delta values were used to identify weekly weight fluctuation trends $[26,34,35]$. For this analysis, BMI delta was defined as the difference between the largest and smallest BMI values in a given week. As such, for each participant, the average weekly BMI values representing their overall obesity level and the weekly BMI deltas indicating their degree of weight fluctuation over 16 weeks were used for the statistical analysis.

\section{Meal History Entry Trends}

As with weight entries, the frequency of self-reported meal history entries has frequently been used in prior studies to address the level of adherence to weight loss intervention programs [4,32]. In this study, participants entered not only their main meals but also snacks in between meals. As participants recorded food items by searching for them within Noom's food database, their eating habits and selections could be grouped in detail by food types.

These food types were categorized as green, yellow, and red groups based on their caloric density, that is, calories per gram or milliliter $[29,30,36]$. In general, foods in the red group have very high caloric density and include foods high in fat and oil $[29,30,36]$. Foods categorized as yellow have moderate caloric density; they are less fatty and oily than the red group but still not optimal $[29,30,36]$. Foods in the green group have very low caloric density and are comprised mostly of natural fruits and vegetables $[29,30,36]$. The applied food type criteria according to caloric density are described in Multimedia Appendix 1.

Variables representing food intake by food type were generated based on the aforementioned criteria. Furthermore, food intake was reported 6 times per day (ie, breakfast, morning snacks, lunch, afternoon snacks, dinner, and evening snacks). This provided a substantial amount of data regarding the changes in food intake for the 3 food groups of each participant over 16 weeks.

\section{Study Sample}

This study was approved by the Institutional Review Board of the Asan Medical Center, Korea (No. 2017-1253). Figure 1 shows the study sample selection procedure. Initially, the study population comprised 5011 users over the age of 18 years who participated in the coaching program from January 1, 2017 to March 5, 2018 [4,37]. Of these, 1440 users were included in the study based on 4 intervention characteristics $[4,9,38]$. First, according to prior research, users who subscribed to the program for at least 16 weeks were included in the study $[4,9,38]$. Second, only users with initial weight information were included in the study, to analyze baseline weight. Third, only those who reported their weight at least once among those who participated in the intervention for at least 13 weeks were included in the study [4]. Finally, 684 overweight and obese users with BMIs $>25 \mathrm{~kg} / \mathrm{m}^{2}$ were selected for analysis [4,36].

Figure 1. Study sample selection process.

(1) Initial population

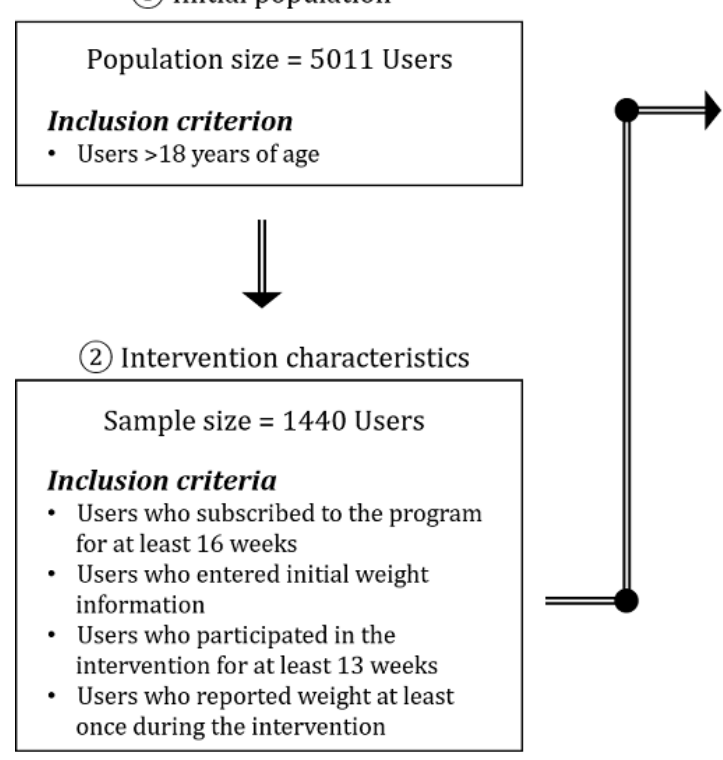

Participants measured their weight on their scales and then reported the weight via the app. To prevent incorrect input that may occur when users report these weight values, certain
(3) Baseline BMI characteristics

Sample size $=684$ Users

Inclusion criterion

- Users with a baseline $\mathrm{BMI} \geq 25 \mathrm{~kg} / \mathrm{m}^{2}$

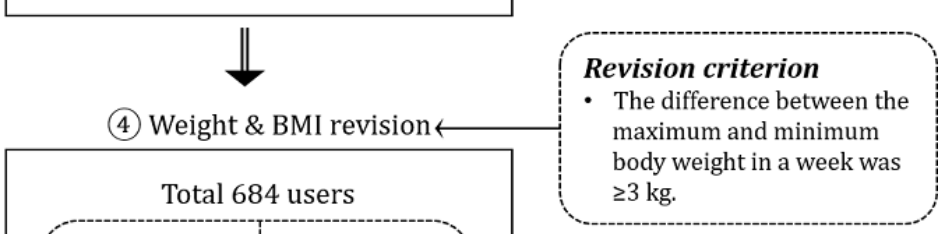

Original

values from

583 users

were

included

Revised

values from

101 users

were

included reported values were corrected. As no previous studies provided any clear criteria for mitigating data errors, a group of three experts consisting of doctors and health care professionals set 
the error criteria and reviewed the data. It was assumed that there could be potential errors if the difference between the maximum weight and minimum weight per week was $\geq 3 \mathrm{~kg}$. The daily weight and BMI values of 101 cases corresponding to this assumption were not included in the weekly averages.

\section{Statistical Analysis}

To analyze the self-reported time-series pattern based on weight loss groups, subjects were divided into 3 groups according to recommendations from prior research [4]. The 3 groups consisted of those with weight losses $<5 \%$, of $5 \%-10 \%$, and $>10 \%$ [4].

Analysis of variance (ANOVA) and chi-squared tests were performed to analyze whether the baseline characteristics of the 3 groups were statistically different. Furthermore, ANOVAs along the time axis were performed to determine whether each measurement (ie, BMI, weight entry, and meal history entry trends) of the 3 groups (ie, $<5 \%, 5 \%-10 \%,>10 \%$ ) within gender were statistically different over 16 weeks. $P$ values were adjusted with the false discovery rate using the Benjamini-Hochberg method, because multiple tests based on the week and groups may yield 5\% false positives at the 5\% significance level [39]. Finally, through slope analysis of each measurement calculated at the aggregated level, the overall time-series trends for the measurements were analyzed.

\section{Results}

\section{Participant Characteristics}

Table 1 shows the test results for the statistical differences in baseline characteristics between the 3 outcome groups. In the case of gender, although few men (19/218) and women (39/466) belonged to the group that lost $>10 \%$ weight, there were no statistical associations among the 3 groups. For age, young participants (ie, mean 32.09 years old) seemed to lose the most weight; however, there were no statistical differences among the 3 groups. In the case of base weight status, the few obese (17/178) participants lost $>10 \%$ of their weight; however, no statistical associations were found among the 3 groups.

Table 1. Participant characteristics for the total sample and according to outcome group.

\begin{tabular}{|c|c|c|c|c|c|}
\hline \multirow[t]{2}{*}{ Characteristics } & \multirow[t]{2}{*}{ Total sample } & \multicolumn{3}{|c|}{ Outcome group according to level of weight loss } & \multirow[t]{2}{*}{$P$ value } \\
\hline & & $<5 \%$ & $5 \%-10 \%$ & $>10 \%$ & \\
\hline \multicolumn{6}{|l|}{ Gender, $n$} \\
\hline Male & $218(31.9)^{\mathrm{a}}$ & 126 & 73 & 19 & $.39^{\mathrm{b}}$ \\
\hline Female & $466(68.1)^{\mathrm{a}}$ & 294 & 133 & 39 & \\
\hline Age (years), mean (SD) & $33.31(7.6)$ & 33.7 & 32.87 & 32.09 & $.19^{\mathrm{c}}$ \\
\hline \multicolumn{6}{|l|}{ Baseline weight status, $n$} \\
\hline Obese & $178(26)^{\mathrm{a}}$ & 112 & 49 & 17 & $.62^{\mathrm{b}}$ \\
\hline Overweight & $506(74)^{\mathrm{a}}$ & 308 & 157 & 41 & \\
\hline
\end{tabular}

\footnotetext{
$\mathrm{a}_{\mathrm{n}}(\%)$.

${ }^{\mathrm{b}}$ Tested differences between the 3 groups using chi-squared tests.

${ }^{\mathrm{c}}$ Tested differences between the 3 groups using analysis of variance (ANOVA).
}

\section{Pattern Analysis}

\section{Weight Entries}

Figure 2 shows the number of weight entries reported by user each week for the 16 weeks. The number of weight entries decreased over time in all 3 groups even though the decreases in the slopes were different (ie, -0.16 for the group who lost
$>10 \%$ of their starting weight, -0.13 for the group who lost $5 \%-10 \%$, and -0.12 for the group who lost $<5 \%$ ). The members of the group with $>10 \%$ weight loss recorded their weight more often in Noom than the other groups (ie, the groups who lost $\leq 10 \%)$. This trend at the aggregated level was statistically significant throughout the entire study period (Table 2). Moreover, the statistical significance of the trend was noticeable in women (Table 2). 
Figure 2. The number of weight entries on a weekly basis over 16 weeks; the colored bands show the 95\% CI.

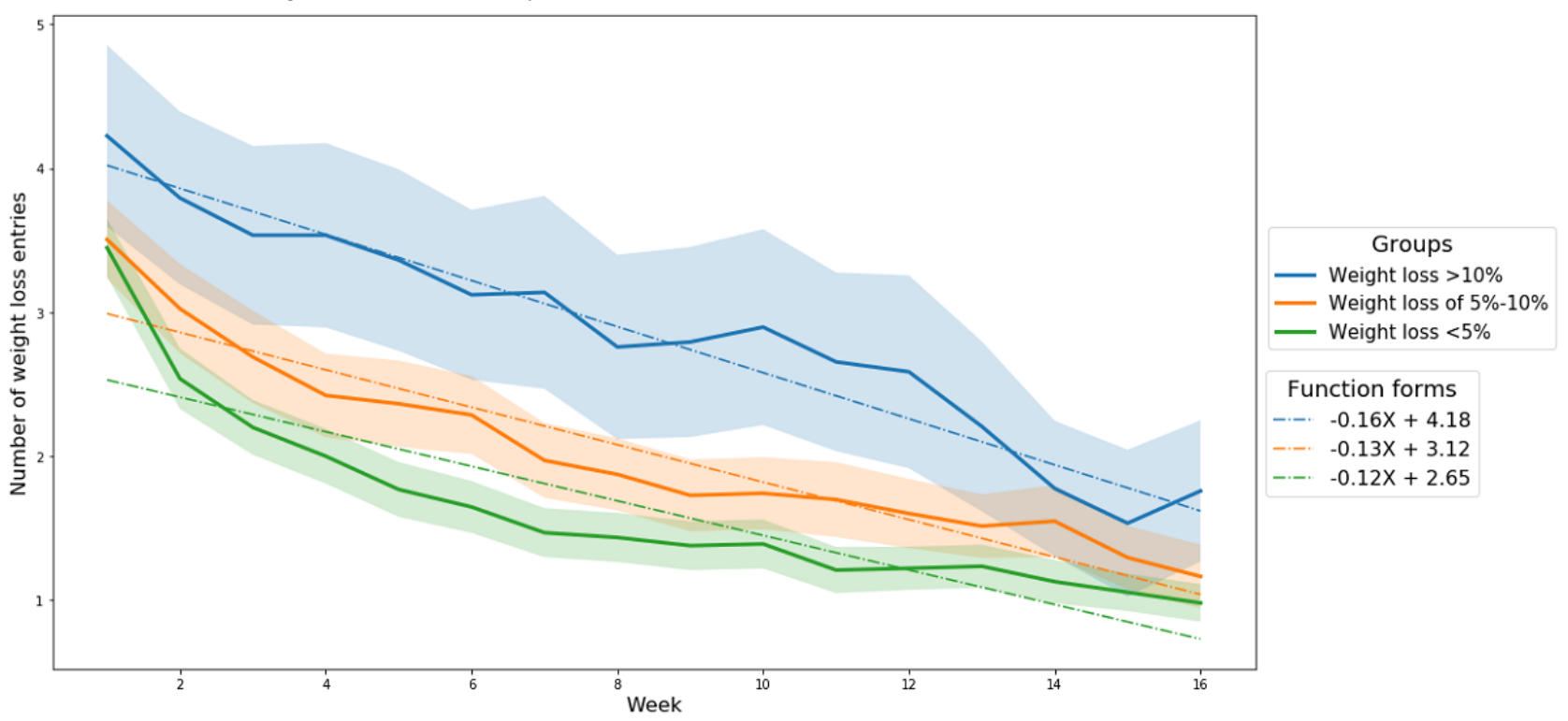

Table 2. Significance of analysis of variance (ANOVA) test results comparing the differences between groups for 16 weeks. $P$ values were adjusted by the false discovery rate using the Benjamini-Hochberg method, and the actual $P$ values are available in Multimedia Appendix 2 .

\begin{tabular}{|c|c|c|c|c|c|c|c|c|c|c|c|c|c|c|c|c|}
\hline \multirow[t]{2}{*}{ Group } & \multicolumn{16}{|c|}{ Week } \\
\hline & 1 & 2 & 3 & 4 & 5 & 6 & 7 & 8 & 9 & 10 & 11 & 12 & 13 & 14 & 15 & 16 \\
\hline \multicolumn{17}{|l|}{ Weight entries } \\
\hline Total $^{\mathrm{a}}$ & $* * \mathrm{~b}$ & $* * * \mathrm{c}$ & $* * * \mathrm{c}$ & $* * * \mathrm{c}$ & $* * * \mathrm{c}$ & $* * * \mathrm{c}$ & $* * * \mathrm{c}$ & $* * * \mathrm{c}$ & $* * * \mathrm{c}$ & $* * * \mathrm{c}$ & $* * * \mathrm{c}$ & $* * * \mathrm{c}$ & $* * * \mathrm{c}$ & $* * * \mathrm{c}$ & $* * \mathrm{~b}$ & $* * * \mathrm{C}$ \\
\hline $\operatorname{Men}^{\mathrm{a}}$ & & & & & $* * \mathrm{~b}$ & $* * \mathrm{~b}$ & & & & $* \mathrm{~d}$ & & & & & & \\
\hline Women $^{\mathrm{a}}$ & $* * * \mathrm{c}$ & $* * * \mathrm{c}$ & $* * * \mathrm{c}$ & $* * * \mathrm{c}$ & $* * * \mathrm{c}$ & $* * * \mathrm{c}$ & $* * * \mathrm{c}$ & $* * * \mathrm{c}$ & $* * * \mathrm{c}$ & $* * * \mathrm{c}$ & $* * * \mathrm{c}$ & $* * * \mathrm{c}$ & $* * * \mathrm{c}$ & $* * * \mathrm{c}$ & & $* * * c$ \\
\hline \multicolumn{17}{|l|}{ BMI values } \\
\hline Total $^{\mathrm{a}}$ & & & & & $*^{\mathrm{d}}$ & $* \mathrm{~d}$ & $* * \mathrm{~b}$ & $* * * \mathrm{c}$ & $* * * \mathrm{c}$ & $* * * \mathrm{c}$ & $* * * \mathrm{c}$ & $* * * \mathrm{c}$ & $* * * \mathrm{c}$ & $* * * \mathrm{c}$ & $* * * \mathrm{c}$ & $* * * c$ \\
\hline $\operatorname{Men}^{\mathrm{a}}$ & & & & & & & & $*^{\mathrm{d}}$ & $* \mathrm{~d}$ & & & $* * \mathrm{~b}$ & $* * \mathrm{~b}$ & $* * \mathrm{~b}$ & $* * \mathrm{~b}$ & $* \mathrm{~d}$ \\
\hline Women $^{\mathrm{a}}$ & & & & & $* \mathrm{~d}$ & & & $* * * \mathrm{c}$ & $* * \mathrm{~b}$ & $* * \mathrm{~b}$ & $* * * \mathrm{c}$ & $* * * \mathrm{c}$ & $* * * \mathrm{c}$ & $* * * \mathrm{c}$ & $* * * \mathrm{c}$ & $* * * c$ \\
\hline \multicolumn{17}{|l|}{ BMI delta $^{d}$} \\
\hline Total $^{\mathrm{a}}$ & $* * * \mathrm{c}$ & $* * * \mathrm{c}$ & $* * * \mathrm{c}$ & $* \mathrm{~d}$ & $* * * \mathrm{c}$ & $* * * \mathrm{c}$ & $* \mathrm{~d}$ & $* * \mathrm{~b}$ & $*^{\mathrm{d}}$ & & $* * * \mathrm{c}$ & $*^{\mathrm{d}}$ & & & & \\
\hline $\mathrm{Men}^{\mathrm{a}}$ & & $* * \mathrm{~b}$ & & & & & & & & & & & & & & \\
\hline Women $^{\mathrm{a}}$ & $* * * \mathrm{c}$ & $* * * \mathrm{c}$ & $* * \mathrm{~b}$ & & $* * * \mathrm{c}$ & $* * * \mathrm{c}$ & $*^{\mathrm{d}}$ & $*^{\mathrm{d}}$ & & & $* * * \mathrm{c}$ & $* * \mathrm{~b}$ & & & & \\
\hline \multicolumn{17}{|c|}{ Meal history entries } \\
\hline $\operatorname{Total}^{\mathrm{a}}$ & & $* \mathrm{~d}$ & $*^{\mathrm{d}}$ & $* * \mathrm{~b}$ & $*^{\mathrm{d}}$ & $* * * \mathrm{c}$ & $* * * \mathrm{c}$ & $* * * \mathrm{c}$ & $* * * \mathrm{c}$ & $* * * \mathrm{c}$ & $* * \mathrm{~b}$ & $* * * \mathrm{c}$ & $* \mathrm{~d}$ & $* * \mathrm{~b}$ & $*^{\mathrm{d}}$ & $* * \mathrm{~b}$ \\
\hline \multicolumn{17}{|l|}{$\mathrm{Men}^{\mathrm{a}}$} \\
\hline Women $^{\mathrm{a}}$ & & & & $*^{\mathrm{d}}$ & $* \mathrm{~d}$ & $* * \mathrm{~b}$ & $* * * \mathrm{c}$ & $* * \mathrm{~b}$ & $* * \mathrm{~b}$ & $* * * \mathrm{c}$ & & $* * * \mathrm{c}$ & $* \mathrm{~d}$ & $* * \mathrm{~b}$ & $* * \mathrm{~b}$ & $* * \mathrm{~b}$ \\
\hline
\end{tabular}

${ }^{\mathrm{a}}$ When the null hypotheses were tested using ANOVA, the three groups (weight loss $>10 \%$, weight loss of 5\%-10\%, and weight loss $<5 \%$ ) had the same value.

${ }^{\mathrm{b}} P<.05$

${ }^{\mathrm{c}} P<.01$

${ }^{\mathrm{d}} P<.1$

${ }^{\mathrm{e}}$ Defined as the difference between the maximum and minimum BMIs in a given week. 


\section{BMI Values}

Figure 3 shows the trend in the BMI values for the 3 groups over time at the aggregated level. The differences in the BMI values between the 3 groups was statistically significant after week 5 (Table 2). Furthermore, the statistical difference was more noticeable in women than in men (Table 2).

In all 3 groups, the BMI delta values - representing the degree of weight fluctuation - were only high during the initial 3 weeks (Figure 4). The group that lost $>10 \%$ weight had larger BMI delta values during the entire study period. The difference in BMI delta values among the 3 groups was the most statistically significant during the first several weeks. However, most of the differences in values became insignificant over time (Table 2). Moreover, the BMI delta was more statistically significant in women (Table 2).

Figure 3. BMIs over 16 weeks according to weight loss outcome groups; the colored bands show the $95 \%$ CI.

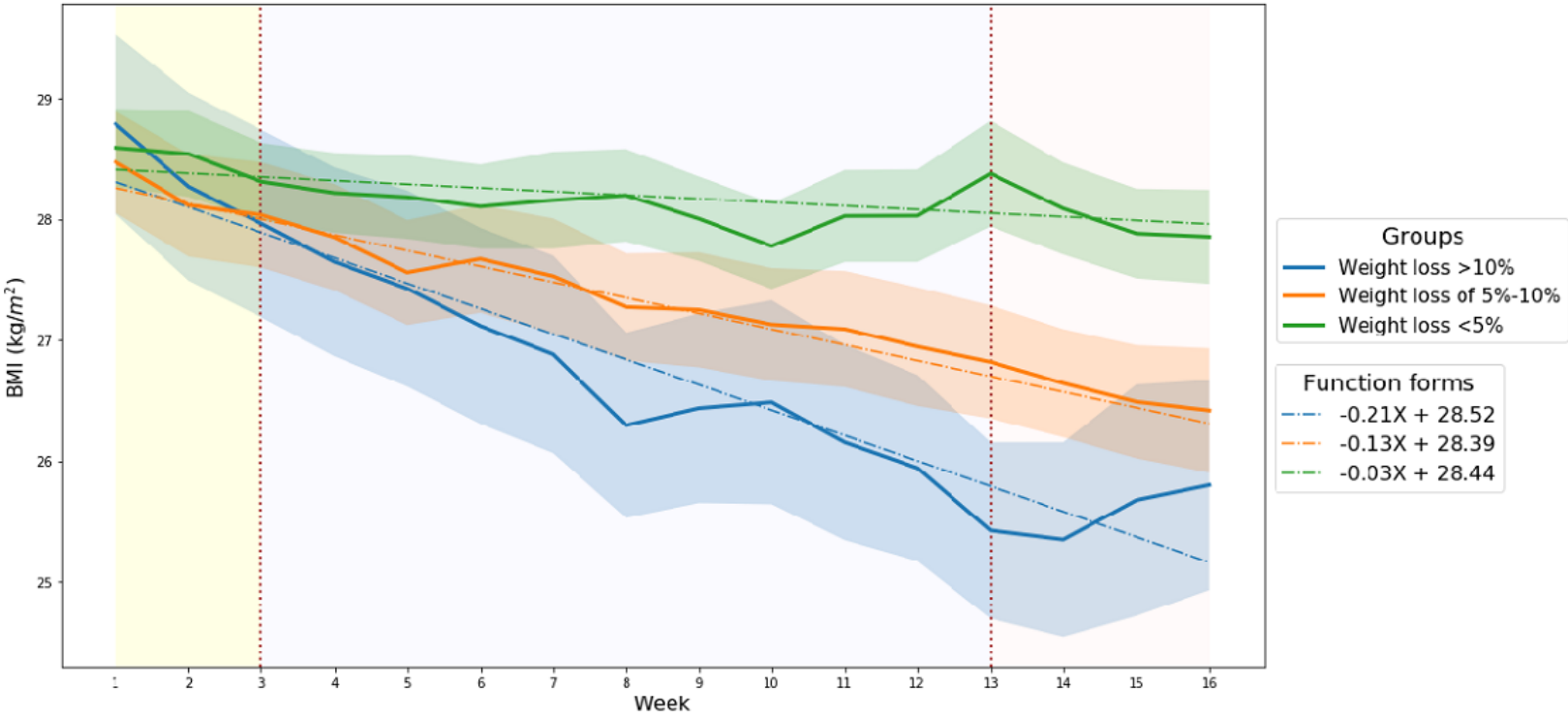

Figure 4. BMI delta over 16 weeks according to weight loss outcome groups; the colored bands show the $95 \%$ CI.

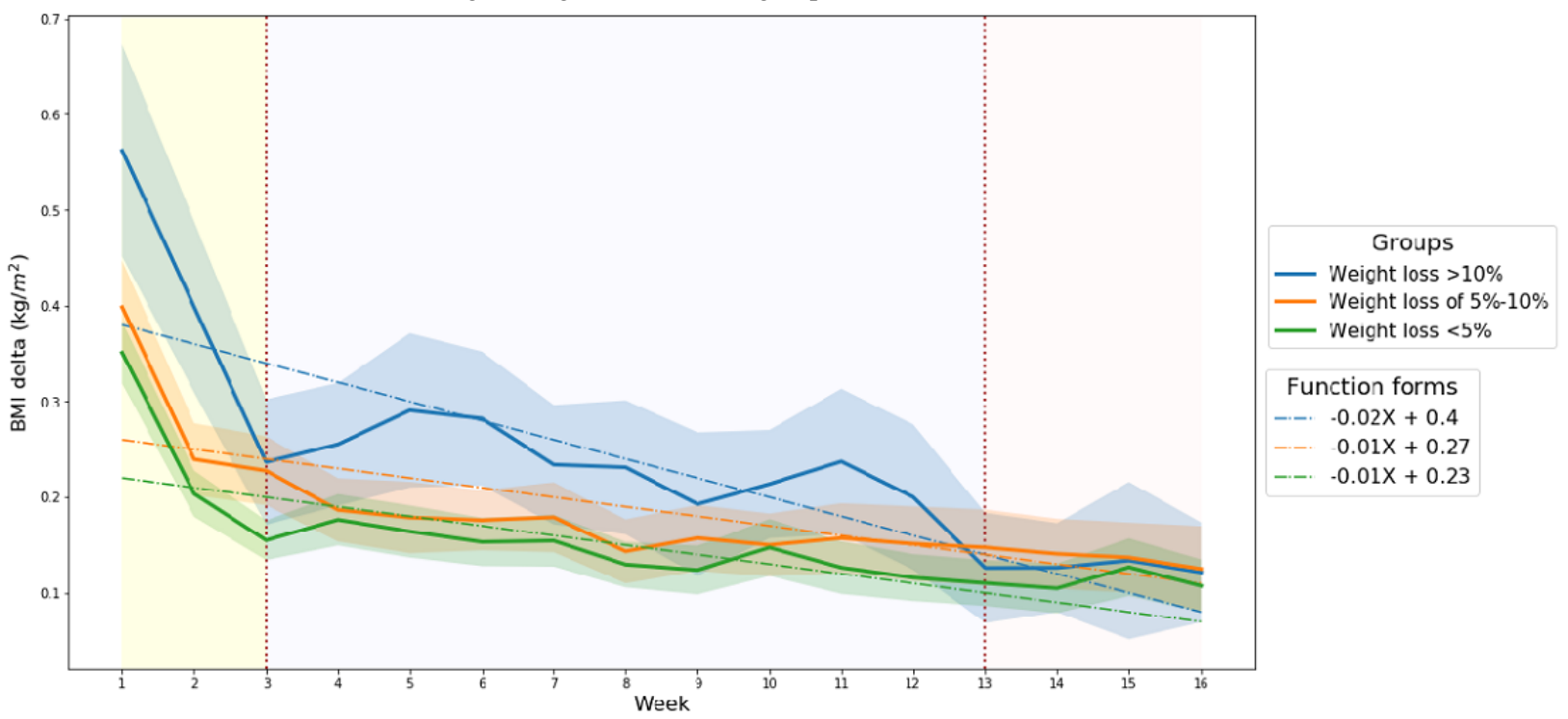

\section{Meal History Entries}

As seen in Figure 5, the number of meal history entries decreased over time in all 3 groups (slope values of -0.67 , -0.77 , and -0.79 for the groups with $>10 \%$ weight loss, $5 \%-10 \%$ weight loss, and $<5 \%$ weight loss, respectively). The 2 groups that reduced their weight by $\geq 5 \%$ had a higher total number of meal history entries than the less successful group, and the differences in total number of meal history entries among the
3 groups were statistically significant during most of the study period (Table 2). No significant differences in the total number of meal history entries were found for men (Table 2). On the other hand, for women, significant differences were found during most of the study period (Table 2).

Table 3 shows food intakes divided into the green, yellow, and red groups for 16 weeks for women. Women had many statistical differences between the yellow and red food groups, especially at lunch and dinner. In particular, when the intake of foods in 
the red category was averaged over all study periods, statistical differences between the 3 groups were significant for all meal types (Table 3). However, for men, there were no statistical differences between weight loss outcome groups and food groups over the 16 weeks.

Figure 5. Number of meal history entries on a weekly basis over 16 weeks; the colored bands show the $95 \%$ CI.

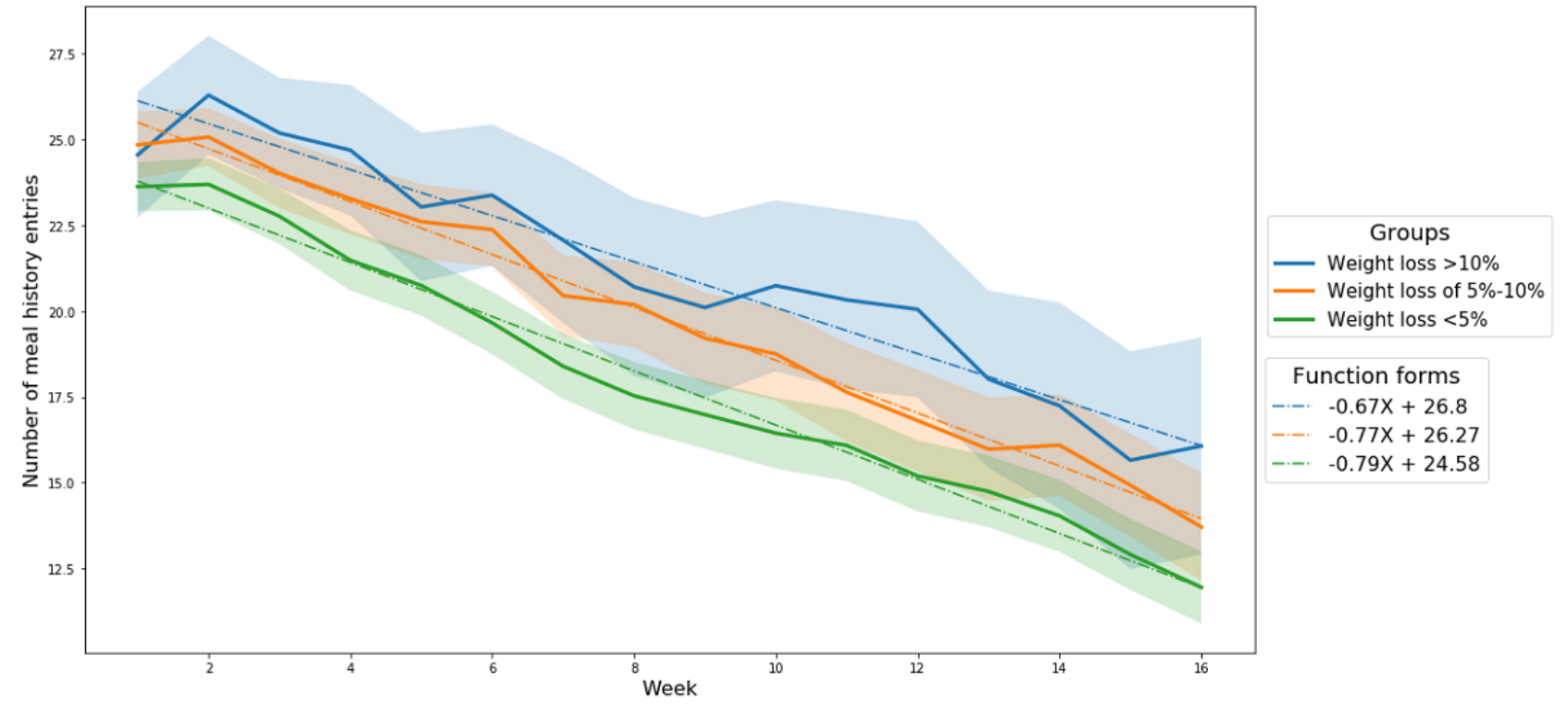


Table 3. Significance of analysis of variance (ANOVA) test results comparing the differences in intake amount by food group (green, yellow, and red) in women for 16 weeks. $P$ values were adjusted with the false discovery rate using the Benjamini-Hochberg method, and the actual $P$ values are available in Multimedia Appendix 3.

\begin{tabular}{|c|c|c|c|c|c|c|c|c|c|c|c|c|c|c|c|c|}
\hline \multirow[t]{2}{*}{ Food group } & \multicolumn{15}{|c|}{ Week } & \\
\hline & 1 & 2 & 3 & 4 & 5 & 6 & 7 & 8 & 9 & 10 & 11 & 12 & 13 & 14 & 15 & $\operatorname{Avg}^{\mathrm{a}}$ \\
\hline
\end{tabular}

\section{Green}

$\mathrm{BRE}^{\mathrm{b}} \quad * * \mathrm{c}$

MOR.S ${ }^{\mathrm{d}}$

$\mathrm{LUN}^{\mathrm{e}}$

AFT.S ${ }^{\mathrm{f}}$

DIN $^{\mathrm{g}}$

EVE.S ${ }^{\text {h }}$

Yellow

BRE

MOR.S

LUN

AFT.S

DIN

EVE.S

Red

BRE

MOR.S

LUN

AFT.S

DIN

EVE.S
$* * \mathrm{c}$

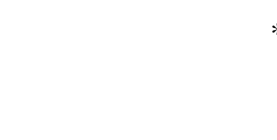

$* *^{\mathrm{c}}$

$* \mathrm{j}$

$* * \mathrm{c} \quad * * \mathrm{c}$

$* * \mathrm{c}$

$* * \mathrm{c} \quad * * \mathrm{c}$

$* * \mathrm{c}$

$* * * \mathrm{i}$

a Avg: grouped average of food intake over 16 weeks; the $P$ value for was not adjusted by the false discovery rate using the Benjamini-Hochbert method. When the null hypotheses were tested using ANOVA, the three groups (weight loss $>10 \%$, weight loss of 5\%-10\%, and weight loss $<5 \%$ ) had the same value.

${ }^{\mathrm{b}} \mathrm{BRE}$ : breakfast.

${ }^{\mathrm{c}} P<.05$

${ }^{\mathrm{d}}$ MOR.S: morning snack.

e LUN: lunch.

${ }^{\mathrm{f}}$ AFT.S: afternoon snack.

g DIN: dinner.

${ }^{\mathrm{h}}$ EVE.S: evening snack.

${ }^{\mathrm{i}} P<.01$

${ }^{\mathrm{j}} P<.1$

\section{Discussion}

\section{Principal Findings}

\section{Decreased Level of Adherence Over Time}

Previous studies showed that the degree of adherence to self-reporting in mobile weight loss intervention programs decreases over time $[4,6,23]$. Going one step further, this study found that adherence decreases over time regardless of weight loss outcomes. Specifically, both the total weight and meal history entries decreased gradually over 16 weeks (Figures 2 and 5). Prior studies had assumed that mobile technology utilization could overcome the low adherence to self-reporting that occurs when utilizing rudimentary paper tools during weight loss interventions [6,13]. Although mobile technology clearly makes self-reporting easier, the results of this study revealed 
that there is a natural tendency to lower one's adherence to self-reporting over time regardless of weight loss outcomes.

Among the many factors that hinder long-term adherence, the most relevant to this study may be the lack of serious awareness of current health conditions [37,40,41]. In general, most people are not likely to feel any ominous threats even if they do not lose their weight right away, and they are prone to stop dieting. Therefore, to promote long-term adherence, it is necessary to provide an environment in which diet participants recognize the critical importance of weight management [42,43]. Given the lessons learned from previous diet studies that have shown that digital push notifications have no effect on adherence, reminding participants regularly about the importance of dieting may be ineffective $[44,45]$. Instead, there seems to be a need for further research to provide divergent strategies for people with obesity.

Conversely, it may be entirely reasonable to simply admit that humans are less committed to interventions over time, especially for slow and arduous tasks like trying to lose weight. In other words, it may be wise to avoid long-term adherence issues that are unlikely to be solved. Rather, the best practice may be to focus on understanding the characteristics of adherence with latent patterns. Recent data science algorithms may be employed to understand specific patterns of adherence. Specifically, the use of time series decomposition algorithms that eliminate the inevitable long-term declines in adherence may be used for exploring repeated patterns of adherence [46,47]. Then, demonstrating the association between the pattern and weight loss outcomes can provide new insights.

\section{Characteristics of BMI Change Over Time}

According to the results of this empirical analysis, BMI changes can be characterized in 3 time series periods (Figures 3 and 4). The first interval is from week 1 to week 3 , where the overall BMI delta value started high and fell rapidly over time and the overall BMI value was high in the initial stages. High values for both BMI and BMI delta may indicate substantial weight fluctuations with low weight losses within a week. This phenomenon may be due to the participants' biological responses to homeostasis (ie, steady weight) [27]. It takes time for the human body to adapt to a diet (ie, limiting caloric intake and increasing energy expenditure through exercise) [27,48,49]. During this adaptation process, human weight can fluctuate based on a variety of factors, including hormones, psychology, and physiology [21-23]. Although the period of adaptation may vary depending on certain factors (eg, race, diet style), several empirical studies have found that it takes human bodies approximately 2 to 4 weeks to adapt to a diet $[48,49]$. Therefore, participants in this study might have experienced weight fluctuations during the dietary adaptation process period.

The second interval is between weeks 3 and 13. This interval was characterized by differences in BMI that increased over time among the outcome groups. Further, most BMI deltas were statistically different among the groups (Figures 3 and 4, Table 2 ). In this period, the differences in weight loss between the successful and unsuccessful diet groups were noticeable. Specifically, the successful group had high BMI deltas and low BMI values, which may indicate that the successful participants lost weight. On the other hand, the unsuccessful group during the same period had low BMI deltas and high BMI values, thereby suggesting that the unsuccessful participants rarely lost any weight at all.

The last interval is between weeks 13 and 16. This interval was characterized by no differences in BMI deltas between the groups (Figure 4). Another feature during this period was the manifestation of weight increases in the group that lost the most weight $(>10 \%)$. This may indicate that the group members stopped trying to lose weight, because people do not lose weight beyond their ideal weight. From a physiological point of view, the feature may be attributed to the widely known "yo-yo" effect that commonly occurs after rapid weight loss [45-47]. The yo-yo effect is defined as a rapid weight gain after a diet. Indeed, many previous studies have shown that the majority of diet participants regain their weight over the long term [45-47]. In this study, the yo-yo effect may have occurred in participants who had dietary laxity as the mobile weight loss intervention program was nearing its end in week 16.

\section{Different Patterns for Female and Male Participants}

Gender effects on the differences in self-reporting adherence have often been discussed in previous studies of weight loss interventions [4,6,22]. Going one step further, this study explored the time-dependent relationships among adherence to self-reporting, gender effects, and weight loss outcomes.

Unlike female participants, male participants had little differences in the number of weight entries among the outcome groups during the 16 weeks (Table 2). Furthermore, in terms of the number of meal history entries, there were no statistical differences in the values among the outcome groups for male participants (Table 2). However, statistical differences in BMI values among the 3 groups were found around the last several weeks (Table 2).

These results suggest that there was no statistical association between adherence to self-reporting and weight loss outcomes in the male population. This contradicts some previous studies that showed positive relationships between the two $[6,7,50]$. Inconsistencies in the results can be addressed as follows. Considering that the tendency to self-report is influenced by various factors, such as gender and race [6,22,51], Korean adult men may not be as inclined to self-report. In other words, they may have avoided timely self-reporting regardless of the success of the diet. As self-reporting itself has no direct effect on weight loss, male participants might have been able to lose weight without consistent self-reporting if they managed their diet well and consistently exercised.

Another interesting finding in this analysis is that the male participants, unlike the female participants, demonstrated no statistical difference in the intake of food types among the 3 weight loss groups. Previous studies found that men were insensitive to food intake during their diets, while women were very sensitive $[52,53]$. Therefore, the results may have captured the food intake characteristics of dieting men during mobile interventions. However, it should be recognized that these characteristics may also depend on other factors such as age or ethnicity [17-19]. Therefore, further research is needed in 
different settings to identify the factors that may contribute to gender differences in self-reporting and weight loss outcomes.

\section{Limitations}

This study has limitations that may inspire future research. First, analysis results cannot be free from errors, as the data are self-reported. Particularly, the weight statistics used to divide participants into 3 weight loss groups were self-reported. Although reporting of actual information was encouraged in the research agreements, potential mistakes could have arisen for which participants could have been unaware while reporting their weight. Furthermore, scales that the participants used may not have been reliable. To prevent these potential problems, some weight values were modified by applying logic during preprocessing. However, the applied logic was empirical and somewhat arbitrary. In addition, all reported data other than weight information, such as gender and age, were assumed to be true and consistent throughout the study. No correction was made for misreported data. Further research should be conducted in more sophisticated environments by collecting data under rigorous verification by researchers or health professionals.

Second, there is a potential limitation related to the approach and data analyses in this study. First, the significance of the $P$ value may have been underpowered. In particular, only $8.7 \%$ $(19 / 218)$ of the male participants lost more than $10 \%$ of their weight (Table 1). Further, only 9.5\% (17/178) of the participants who were obese before they started the experiment lost more than $10 \%$ of their weight (Table 1). The small sample size could have potentially undermined statistical significance [54]. Second, the interval division criteria applied to the analysis of BMI and BMI delta values are somehow arbitrary. Although methodologies exist for determining trend-change points, such methodologies may not provide adequate solutions in short-term multivariate time-series environments (ie, 16 weeks with 6 series) [55]. Thus, a more rigorous data analysis setting should be established by collecting more data and applying sophisticated approaches.

Third, there may be potential limitations in the experimental setting assumptions. For instance, although the registered dietitians in the program did not recommend the use of weight-reducing drugs like diuretics, some participants might have relied on some medicines that have a huge effect on weight loss. Furthermore, the study design did not include a control group, which might have undermined the ability to evaluate the efficacy of the mobile weight loss intervention. For example, the weights of the subjects who canceled the program prior to week 13 were not analyzed. By analyzing such data in a control group, the efficacy of the mobile intervention can be evaluated in a more rigorous manner. In addition, significant differences in food intake reporting by weight loss outcomes in female participants may have been caused by the Hawthorne effect [56]. In other words, the significant difference may be the result of a keen sense of being observed in the experiment rather than gender. Therefore, further experimentations with more sophisticated settings are essential.

Fourth, two factors may have undermined the representativeness of self-reported data for measurements. First, the number of self-reported entries may not have measured spontaneous adherence levels, because the app provides push notifications to remind users to report their data. Additionally, as the degree of self-reporting decreases over time, the data may be insufficient for representing weight status. Particularly, the average number of weight entries in the 16th week for the lowest weight loss group $(<5 \%)$ was less than 1.5 per participant. When body weight is reported only once per week, potentially biased values may have been reported depending on the timing of the report (eg, after exercise or immediately after main meals, mornings versus evenings). Therefore, for studies requiring self-reporting, further discussion is required regarding data collection and analytical approaches.

\section{Conclusions}

Mobile technology has increased the convenience of self-reporting when dieting [6,13]. However, it should be noted that technology is not the essence of weight loss; rather, it provides a stimulus through simplified self-reporting that may have positive effects on weight loss. Therefore, further research should be conducted to determine ways to couple mobile technology with human nature to foster more effective dieting and consistently healthy lifestyles.

\section{Acknowledgments}

This study was supported by a grant from the Research and Development Project, Ministry of Trade, Industry, and Energy, Republic of Korea (no. 20004503).

\section{Conflicts of Interest}

YK is employed at Noom and has conflicts of interest. All other authors declare no conflicts of interest.

\section{Multimedia Appendix 1}

Food-type criteria according to caloric density. [PDF File (Adobe PDF File), 68 KB-Multimedia Appendix 1]

\section{Multimedia Appendix 2}

$\mathrm{P}$ values from the ANOVA tests comparing the differences between groups for 16 weeks. [PDF File (Adobe PDF File), 87 KB-Multimedia Appendix 2] 


\section{Multimedia Appendix 3}

$\mathrm{P}$ values from the ANOVA tests comparing the differences in intake amount by food group (green, yellow, and red) in women for 16 weeks.

[PDF File (Adobe PDF File), 176 KB-Multimedia Appendix 3]

\section{References}

1. Lee W, Chae YM, Kim S, Ho SH, Choi I. Evaluation of a mobile phone-based diet game for weight control. J Telemed Telecare 2010 Jun;16(5):270-275. [doi: 10.1258/jtt.2010.090913] [Medline: 20558620]

2. Toro-Ramos T, Lee D, Kim Y, Michaelides A, Oh TJ, Kim KM, et al. Effectiveness of a Smartphone Application for the Management of Metabolic Syndrome Components Focusing on Weight Loss: A Preliminary Study. Metab Syndr Relat Disord 2017 Nov;15(9):465-473. [doi: 10.1089/met.2017.0062] [Medline: 29035677]

3. Jeon E, Park H. Development of a smartphone application for clinical-guideline-based obesity management. Healthc Inform Res 2015 Jan;21(1):10-20 [FREE Full text] [doi: 10.4258/hir.2015.21.1.10] [Medline: 25705553]

4. Painter SL, Ahmed R, Hill JO, Kushner RF, Lindquist R, Brunning S, et al. What Matters in Weight Loss? An In-Depth Analysis of Self-Monitoring. J Med Internet Res 2017 May 12;19(5):e160 [FREE Full text] [doi: 10.2196/jmir.7457] [Medline: 28500022]

5. Laitner MH, Minski SA, Perri MG. The role of self-monitoring in the maintenance of weight loss success. Eat Behav 2016 Apr;21:193-197 [FREE Full text] [doi: 10.1016/j.eatbeh.2016.03.005] [Medline: 26974582]

6. Burke LE, Wang J, Sevick MA. Self-monitoring in weight loss: a systematic review of the literature. J Am Diet Assoc 2011 Jan;111(1):92-102 [FREE Full text] [doi: 10.1016/j.jada.2010.10.008] [Medline: 21185970]

7. Baker RC, Kirschenbaum DS. Self-monitoring may be necessary for successful weight control. Behavior Therapy 1993;24(3):377-394. [doi: 10.1016/S0005-7894(05)80212-6]

8. Zheng Y, Klem ML, Sereika SM, Danford CA, Ewing LJ, Burke LE. Self-weighing in weight management: a systematic literature review. Obesity (Silver Spring) 2015 Feb 17;23(2):256-265 [FREE Full text] [doi: 10.1002/oby.20946] [Medline: 25521523]

9. Cadmus-Bertram L, Marcus BH, Patterson RE, Parker BA, Morey BL. Use of the Fitbit to Measure Adherence to a Physical Activity Intervention Among Overweight or Obese, Postmenopausal Women: Self-Monitoring Trajectory During 16 Weeks. JMIR Mhealth Uhealth 2015 Nov 19;3(4):e96 [FREE Full text] [doi: 10.2196/mhealth.4229] [Medline: 26586418]

10. Kanfer FH. Self-monitoring: Methodological limitations and clinical applications. Journal of Consulting and Clinical Psychology 1970;35(2):148-152. [doi: 10.1037/h0029874]

11. Burke LE, Warziski M, Starrett T, Choo J, Music E, Sereika S, et al. Self-monitoring dietary intake: current and future practices. J Ren Nutr 2005 Jul;15(3):281-290. [doi: 10.1016/j.jrn.2005.04.002] [Medline: 16007557]

12. Helsel DL, Jakicic JM, Otto AD. Comparison of techniques for self-monitoring eating and exercise behaviors on weight loss in a correspondence-based intervention. J Am Diet Assoc 2007 Oct;107(10):1807-1810. [doi: 10.1016/j.jada.2007.07.014] [Medline: 17904942]

13. Beasley J. The pros and cons of using PDAs for dietary self-monitoring. J Am Diet Assoc 2007 May;107(5):739; author reply 739-739; author reply 740. [doi: 10.1016/j.jada.2007.03.023] [Medline: 17467366]

14. Bravata DM, Smith-Spangler C, Sundaram V, Gienger AL, Lin N, Lewis R, et al. Using pedometers to increase physical activity and improve health: a systematic review. JAMA 2007 Nov 21;298(19):2296-2304. [doi: 10.1001/jama.298.19.2296] [Medline: 18029834]

15. Helander EE, Vuorinen A, Wansink B, Korhonen IKJ. Are breaks in daily self-weighing associated with weight gain? PLoS One 2014 Nov;9(11):e113164 [FREE Full text] [doi: 10.1371/journal.pone.0113164] [Medline: 25397613]

16. Webber KH, Tate DF, Ward DS, Bowling JM. Motivation and its relationship to adherence to self-monitoring and weight loss in a 16-week Internet behavioral weight loss intervention. J Nutr Educ Behav 2010 May;42(3):161-167. [doi: 10.1016/j.jneb.2009.03.001] [Medline: 20138583]

17. Li W, Youssef G, Procter-Gray E, Olendzki B, Cornish T, Hayes R, et al. Racial Differences in Eating Patterns and Food Purchasing Behaviors among Urban Older Women. J Nutr Health Aging 2017 Nov 5;21(10):1190-1199 [FREE Full text] [doi: 10.1007/s12603-016-0834-7] [Medline: 29188879]

18. Wang Y, Chen X. How much of racial/ethnic disparities in dietary intakes, exercise, and weight status can be explained by nutrition- and health-related psychosocial factors and socioeconomic status among US adults? J Am Diet Assoc 2011 Dec;111(12):1904-1911 [FREE Full text] [doi: 10.1016/j.jada.2011.09.036] [Medline: 22117667]

19. Wirtz JG, Kulpavaropas S. The effects of narrative and message framing on engagement and eating intention among a sample of adult Hispanics. J Nutr Educ Behav 2014 Sep;46(5):396-400. [doi: 10.1016/j.jneb.2013.12.005] [Medline: 24517968]

20. Chin SO, Keum C, Woo J, Park J, Choi HJ, Woo J, et al. Successful weight reduction and maintenance by using a smartphone application in those with overweight and obesity. Sci Rep 2016 Nov 07;6(1):34563 [FREE Full text] [doi: 10.1038/srep34563] [Medline: 27819345] 
21. Comulada WS, Swendeman D, Koussa MK, Mindry D, Medich M, Estrin D, et al. Adherence to self-monitoring healthy lifestyle behaviours through mobile phone-based ecological momentary assessments and photographic food records over 6 months in mostly ethnic minority mothers. Public Health Nutr 2017 Dec 04;21(4):679-688. [doi: 10.1017/s1368980017003044]

22. Hollis JF, Gullion CM, Stevens VJ, Brantley PJ, Appel LJ, Ard JD, Weight Loss Maintenance Trial Research Group. Weight loss during the intensive intervention phase of the weight-loss maintenance trial. Am J Prev Med 2008 Aug;35(2):118-126 [FREE Full text] [doi: 10.1016/j.amepre.2008.04.013] [Medline: 18617080]

23. Glover M, Nolte M, Wagemakers A, McRobbie H, Kruger R, Breier BH, et al. Adherence to daily dietary and activity goals set within a Māori and Pacific weight loss competition. BMC Obes 2019 Mar 4;6(1):6 [FREE Full text] [doi: 10.1186/s40608-019-0228-6] [Medline: 30867932]

24. Asbjørnsen RA, Smedsrød ML, Solberg Nes L, Wentzel J, Varsi C, Hjelmesæth J, et al. Persuasive System Design Principles and Behavior Change Techniques to Stimulate Motivation and Adherence in Electronic Health Interventions to Support Weight Loss Maintenance: Scoping Review. J Med Internet Res 2019 Jun 21;21(6):e14265 [FREE Full text] [doi: 10.2196/14265] [Medline: 31228174$]$

25. Kim Y, Oh B, Shin H. Effect of mHealth With Offline Antiobesity Treatment in a Community-Based Weight Management Program: Cross-Sectional Study. JMIR Mhealth Uhealth 2020 Jan 21;8(1):e13273 [FREE Full text] [doi: 10.2196/13273] [Medline: $\underline{31961335]}$

26. Foreyt JP, Brunner RL, Goodrick GK, Cutter G, Brownell KD, St. Jeor ST. Psychological correlates of weight fluctuation. Int. J. Eat. Disord 1995 Apr;17(3):263-275. [doi: 10.1002/1098-108x(199504)17:3<263::aid-eat2260170307>3.0.co;2-n]

27. Maclean PS, Bergouignan A, Cornier M, Jackman MR. Biology's response to dieting: the impetus for weight regain. Am J Physiol Regul Integr Comp Physiol 2011 Sep;301(3):R581-R600 [FREE Full text] [doi: 10.1152/ajpregu.00755.2010] [Medline: 21677272]

28. Voelker R. Improved use of BMI needed to screen children for overweight. JAMA 2007 Jun 27;297(24):2684-2685. [doi: 10.1001/jama.297.24.2684] [Medline: 17595264]

29. Beleigoli AM, Andrade AQ, Cançado AG, Paulo MN, Diniz MDFH, Ribeiro AL. Web-Based Digital Health Interventions for Weight Loss and Lifestyle Habit Changes in Overweight and Obese Adults: Systematic Review and Meta-Analysis. J Med Internet Res 2019 Jan 08;21(1):e298 [FREE Full text] [doi: 10.2196/jmir.9609] [Medline: $\underline{\text { 30622090] }}$

30. Gray DS, Fujioka K. Use of relative weight and body mass index for the determination of adiposity. Journal of Clinical Epidemiology 1991 Jan;44(6):545-550. [doi: 10.1016/0895-4356(91)90218-x]

31. Doucet E, St-Pierre S, Alméras N, Tremblay A. Relation between appetite ratings before and after a standard meal and estimates of daily energy intake in obese and reduced obese individuals. Appetite 2003 Feb;40(2):137-143. [doi: 10.1016/s0195-6663(02)00143-5]

32. Nagpal TS, Prapavessis H, Campbell C, Mottola MF. Measuring Adherence to a Nutrition and Exercise Lifestyle Intervention: Is Program Adherence Related to Excessive Gestational Weight Gain? Behav Anal Pract 2017 Dec 17;10(4):347-354 [FREE Full text] [doi: 10.1007/s40617-017-0189-5] [Medline: 29214130]

33. Kim J, Lim S, Min YH, Shin Y, Lee B, Sohn G, et al. Depression Screening Using Daily Mental-Health Ratings from a Smartphone Application for Breast Cancer Patients. J Med Internet Res 2016 Aug 04;18(8):e216 [FREE Full text] [doi: 10.2196/jmir.5598] [Medline: 27492880]

34. Kimokoti R, Newby P, Gona P, Zhu L, Jasuja G, Pencina M, et al. Diet quality, physical activity, smoking status, and weight fluctuation are associated with weight change in women and men. J Nutr 2010 Jul;140(7):1287-1293 [FREE Full text] [doi: 10.3945/jn.109.120808] [Medline: 20484553]

35. Heatherton TF, Polivy J, Herman CP. Restraint, weight loss, and variability of body weight. Journal of Abnormal Psychology 1991;100(1):78-83. [doi: 10.1037/0021-843x.100.1.78]

36. Ma C, Avenell A, Bolland M, Hudson J, Stewart F, Robertson C, et al. Effects of weight loss interventions for adults who are obese on mortality, cardiovascular disease, and cancer: systematic review and meta-analysis. BMJ 2017 Nov 14;359:j4849 [FREE Full text] [doi: 10.1136/bmj.j4849] [Medline: 29138133]

37. Poobalan AS, Aucott LS, Precious E, Crombie IK, Smith WCS. Weight loss interventions in young people (18 to 25 year olds): a systematic review. Obes Rev 2010 Aug;11(8):580-592. [doi: 10.1111/j.1467-789X.2009.00673.x] [Medline: 19874531]

38. Volpp KG, John LK, Troxel AB, Norton L, Fassbender J, Loewenstein G. Financial incentive-based approaches for weight loss: a randomized trial. JAMA 2008 Dec 10;300(22):2631-2637 [FREE Full text] [doi: 10.1001/jama.2008.804] [Medline: 19066383]

39. Benjamini Y, Hochberg Y. Controlling the False Discovery Rate: A Practical and Powerful Approach to Multiple Testing. Journal of the Royal Statistical Society: Series B (Methodological) 2018 Dec 05;57(1):289-300. [doi: 10.1111/j.2517-6161.1995.tb02031.x]

40. RAYNOR HA, KILANOWSKI CK, ESTERLIS I, EPSTEIN LH. A cost-analysis of adopting a healthful diet in a family-based obesity treatment program. Journal of the American Dietetic Association 2002 May;102(5):645-656. [doi: 10.1016/s0002-8223(02)90148-3] 
41. Epstein LH, Paluch RA, Beecher MD, Roemmich JN. Increasing healthy eating vs. reducing high energy-dense foods to treat pediatric obesity. Obesity (Silver Spring) 2008 Feb;16(2):318-326 [FREE Full text] [doi: 10.1038/oby.2007.61] [Medline: 18239639]

42. Jin J, Sklar GE, Min Sen Oh V, Chuen Li S. Factors affecting therapeutic compliance: A review from the patient's perspective. Ther Clin Risk Manag 2008 Feb;4(1):269-286 [FREE Full text] [doi: 10.2147/tcrm.s1458] [Medline: 18728716]

43. Atinga RA, Yarney L, Gavu NM. Factors influencing long-term medication non-adherence among diabetes and hypertensive patients in Ghana: A qualitative investigation. PLoS One 2018;13(3):e0193995 [FREE Full text] [doi: 10.1371/journal.pone.0193995] [Medline: 29590156]

44. Gill S, Panda S. A Smartphone App Reveals Erratic Diurnal Eating Patterns in Humans that Can Be Modulated for Health Benefits. Cell Metab 2015 Nov 03;22(5):789-798 [FREE Full text] [doi: 10.1016/j.cmet.2015.09.005] [Medline: 26411343]

45. Freyne J, Yin J, Brindal E, Hendrie GA, Berkovsky S, Noakes M. Push Notifications in Diet Apps: Influencing Engagement Times and Tasks. International Journal of Human-Computer Interaction 2017 Feb 06;33(10):833-845. [doi: $10.1080 / 10447318.2017 .1289725]$

46. Verbesselt J, Hyndman R, Newnham G, Culvenor D. Detecting trend and seasonal changes in satellite image time series. Remote Sensing of Environment 2010 Jan;114(1):106-115. [doi: 10.1016/j.rse.2009.08.014]

47. Bergmeir C, Hyndman R, Benítez J. Bagging exponential smoothing methods using STL decomposition and Box-Cox transformation. International Journal of Forecasting 2016 Apr;32(2):303-312. [doi: 10.1016/j.ijforecast.2015.07.002]

48. Lambert EV, Speechly DP, Dennis SC, Noakes TD. Enhanced endurance in trained cyclists during moderate intensity exercise following 2 weeks adaptation to a high fat diet. Eur J Appl Physiol 1994 Oct;69(4):287-293. [doi: $10.1007 / \mathrm{bf00392032]}$

49. Hall KD, Chen KY, Guo J, Lam YY, Leibel RL, Mayer LE, et al. Energy expenditure and body composition changes after an isocaloric ketogenic diet in overweight and obese men. Am J Clin Nutr 2016 Aug 06;104(2):324-333 [FREE Full text] [doi: 10.3945/ajcn.116.133561] [Medline: 27385608]

50. Bray G, Bouchard C. Handbook of obesity: clinical applications. New York: Marcel Dekker; 2004. URL: http://www. crcnetbase.com/isbn/9780824758622 [accessed 2019-10-03]

51. Burke LE, Swigart V, Warziski Turk M, Derro N, Ewing LJ. Experiences of self-monitoring: successes and struggles during treatment for weight loss. Qual Health Res 2009 Jun;19(6):815-828 [FREE Full text] [doi: 10.1177/1049732309335395] [Medline: 19365099]

52. Kiefer I, Rathmanner T, Kunze M. Eating and dieting differences in men and women. The Journal of Men's Health \& Gender 2005 Jun;2(2):194-201. [doi: 10.1016/j.jmhg.2005.04.010]

53. Rolls BJ, Fedoroff IC, Guthrie JF. Gender differences in eating behavior and body weight regulation. Health Psychology 1991;10(2):133-142. [doi: 10.1037//0278-6133.10.2.133] [Medline: 2055211]

54. Biau D, Kernéis S, Porcher R. Statistics in brief: the importance of sample size in the planning and interpretation of medical research. In: Clin Orthop Relat Res. Statistics in brief: the importance of sample size in the planning and interpretation of medical research. Clin Orthop Springer; Sep 2008:2282-2288.

55. James NA, Matteson DS. ecp : An Package for Nonparametric Multiple Change Point Analysis of Multivariate Data. J. Stat. Soft 2014;62(7):1-25. [doi: 10.18637/jss.v062.i07]

56. McCarney R, Warner J, Iliffe S, van Haselen R, Griffin M, Fisher P. The Hawthorne Effect: a randomised, controlled trial. BMC Med Res Methodol 2007 Jul 03;7(1):30 [FREE Full text] [doi: 10.1186/1471-2288-7-30] [Medline: 17608932]

\section{Abbreviations}

ANOVA: analysis of variance.

Edited by G Eysenbach; submitted 17.12.19; peer-reviewed by P Pantoja Bustillos, A Leichtle, S Comulada; comments to author 01.03.20; revised version received 02.04.20; accepted 03.06.20; published 11.08.20

Please cite as:

Kim J, Kam HJ, Kim Y, Lee Y, Lee JH

Understanding Time Series Patterns of Weight and Meal History Reports in Mobile Weight Loss Intervention Programs: Data-Driven Analysis

J Med Internet Res 2020;22(8):e17521

URL: https://www.jmir.org/2020/8/e17521

doi: $10.2196 / 17521$

PMID: $\underline{32780028}$ 
CJunetae Kim, Hye Jin Kam, Youngin Kim, Yura Lee, Jae-Ho Lee. Originally published in the Journal of Medical Internet Research (http://www.jmir.org), 11.08.2020. This is an open-access article distributed under the terms of the Creative Commons Attribution License (https://creativecommons.org/licenses/by/4.0/), which permits unrestricted use, distribution, and reproduction in any medium, provided the original work, first published in the Journal of Medical Internet Research, is properly cited. The complete bibliographic information, a link to the original publication on http://www.jmir.org/, as well as this copyright and license information must be included. 